\title{
The Impact of Cooperation on Business Innovation in Developing Countries: Evidence from Chile in Latin America
}

\author{
Rodrigo Fuentes-Solís ${ }^{*}$, Ariel Soto-Caro², Dusan Paredes ${ }^{3}$
}

\begin{abstract}
There is abundant empirical evidence supporting the relationship between cooperation and innovative entrepreneurial activity, but the conversation continues to be limited to the context of developing countries. This study contributes to the academic debate on this topic with an empirical evaluation of the effect of cooperation networks on innovation, using Chile in Latin America as a case study. Furthermore, while previous studies mainly refer to technological innovations in a particular industrial sector, in this paper we will build an innovation measurement system that incorporates both technological and non-technological activities among diverse industrial sectors. Upon applying cross-sectional data from a national survey on innovation in a developing firm from two different years to a zero-inflated negative binomial regression, we found that a business that reports on cooperation conducts more innovative activities per year compared to one that does not. The type of agent that a business cooperates with is also relevant in this context; other businesses, clients, and consultants showed stronger and more stable results than other types of agents. This evidence is relevant as it presents new information about the importance of the type of agent that a business cooperates with in the context of developing countries.
\end{abstract}

Keywords: Business Innovation; Cooperation; Developing Country

Submitted: March 28 ${ }^{\text {th }}, 2019$ / Approved: November $19^{\text {th }}, 2019$

\section{Highlights:}

- $\quad$ Previous studies mainly refer to technological innovations in a particular industrial sector and in the context of developed countries.

- In this work, we built an innovation measurement system that incorporates both technological and non-technological activities among diverse industrial sectors.

- The type of agent that a business cooperates with is relevant in the context of a developing country. Particularly, cooperating with other businesses, clients, and consultants showed stronger and more stable results compared to cooperating with other types of agents.

- We believe that our results contribute to the discussion about innovation and cooperation, given that we found differences in how businesses address cooperation when the context they are in is different.

\section{Introduction}

While empirical literature positively correlates cooperation with innovation (Fagerberg, Mowery, \& Nelson, 2006b), the evidence is focused mainly on technological innovations (invention patents), and only in the context of developed countries. This inhibits an understanding of the role of cooperation in less developed countries and hides the crucial role that alternative innovations, like non-technological ones, can play. Pippel (2004) highlights this situation, indicating that Research and Development (R\&D) literature almost exclusively centers on technological innovations, ignoring the fact that countries with a mid-to-low level of human capital might prefer innovations that are organizational or not directly related to technology. This leads us to ask, is the relationship between cooperation and innovation different in developing markets? Furthermore, is technological innovation only a partial vision of the concept of current innovation?

There is literature in favor of the idea that developed and developing countries present differences in innovation processes. K. Zhu, Kraemer, \& Xu (2006) studied the process of firms adopting new technologies, maintaining that the preparation of technology, its integration, firm size, global reach, management obstacles, competition intensity, and regulatory environment all influence the assimilation of e-commerce within firms. They used data from 1,857 firms from 10 countries to test their conceptual model. Among their main results, the economic environments that configure innovation assimilation stand out. In particular, the regulatory environment plays a more important role in developing countries than in developed ones. On the other hand, while technology is the most important factor in facilitating assimilation in developing countries, technological integration has proven to be stronger in developed countries.

Technology is only a partial look at innovation, but it sets a valuable precedent that allows us to measure and compare contexts. During the 2007-2012 period, Chile obtained 12 annual patent families on average. The total measure for the same period in the OECD rises to 48,242 patent families (Fuentes Solís \& Ferrada Rubio, 2016). The aforementioned demonstrates both the enormous technological difference between developed and developing countries, and that Chile, given the information available, proves to be a particularly interesting case study. Beyond the country context and without downplaying the significance of technology, the importance of non-technological

1) Universidad de Talca

2) Escuela de Administración y Negocios, Universidad de Concepción campus Chillán

3) Departamento de Economía, Universidad Católica del Norte

*Corresponding author: rodrigo.fuentes@utalca.cl 
innovations is increasingly gaining momentum. H. Zhu, Zhang, \& Lin (2016) examined the case of China's mobile phone manufacturing industry between 1998 and 2008 and provided evidence that in the context of emerging markets, innovations in business models help to increase the market shares of firms that have more limited resources. The work of Heredia Pérez, Geldes, Kunc, \& Flores (2019) also contributes to a broader look at innovation, as its analysis considers both technological and non-technological innovations.

Pippel (2014) studied the impact of cooperation in R\&D on the performance of firms' non-technological innovations. It distinguishes between seven different types of cooperation partners. The study takes data from German firms and uses a logit for the econometric analysis. The work shows that $\mathrm{R} \& \mathrm{D}$ cooperation increases the probability that a firm will introduce non-technological innovations. In addition, R\&D cooperation with providers, consultants, and other firms within the same group of firms and universities have a positive and significant impact on the performance of organizational and marketing innovation. This study presents remarkable empirical evidence focused on non-technological innovations in a developed country. Wadho \& Chaudhry (2018) studied innovation in a developing country by analyzing clothing and textile manufacturers in Pakistan. While the article does not center its focus on cooperation, it presents interesting evidence on factors that drive businesses to innovate in the context of a developing country.

The existing literature centered on evidence from developed countries and groups three types of links between innovation and cooperation: formal, informal, and multi-part (Fagerberg, Mowery, \& Nelson, 2006b). Regarding formal connections, this suggests a positive and significant relationship between the formation of alliances and innovation, a relationship that remains significant across industries and economic sectors (Fagerberg, Mowery, \& Nelson, 2006b). The majority of these studies are centered on high-technology industries, and generally use patents as measures of innovation. Among the diverse arguments that support the relationship between cooperation and innovation we find: the density of the bonds that facilitate the exchange of knowledge, mutual learning, and rapid response capabilities (Dyer, 1996; Dyer \& Nobeoka, 2000). Various studies also argue that the exchange of complex information is reinforced by deep bonds, which suggests that informal bonds also have the potential to make a significant contribution to innovation. Powell (1996) maintains that formal relations are preserved primarily in informal relationships. Hippel (1987) studied information exchange between American steel-producing firms, using interviews with plant managers and other engineers with direct knowledge of the manufacturing processes. When social-professional relationships among engineers in rival firms were particularly close, more exclusive information was exchanged. Many of the studies on networks and innovation have examined the bonds where more than two parties interact. (Rosenkpf \& Tushman, 1998) highlight the importance of the multi-parties that connect technical professionals among organizations. The work of Friedman \& Carmeli (2017) also provides evidence on the importance of networks or connections at the time of innovation. They presented data compiled from 149 small businesses and indicated that the link between strategic decision capacity and innovative behavior was stronger when the relationships between the members were characterized by a high level of connectivity.

Given that we are especially interested in the types of agents that firms choose when innovating, we needed a broader theoretical framework that allowed us to isolate the effect of the types of agents while simultaneously controlling other effects through the relevant dimensions or variable groups that participate in this phenomenon. Some key factors at the time of innovating are the personal characteristics of the owners: age, education, and management style (Fagerberg, Mowery, \& Nelson, 2006a). Other authors incorporate characteristics such as size, exports, debt, firm age, legal incorporation, and product diversification (de Mel, McKenzie, \& Woodruff, 2009). Along this line, Marsh (2004) highlights seven groups of variables or dimensions that influence the decision to innovate: idea stock, market demand for a new product, technological opportunities, market structure, firm characteristics, appropriability of the new product or process, and the interaction between institutions and institutional factors. While we recognize the relevancy of each one of these groups of variables proposed by the authors, our study cannot consider all of them, mainly due to information limitations. However, the available information allows us to approximate four groups or dimensions of variables: 1 ) Human capital. The number of workers or employees and the proportion of professionals and technicians. 2) Market. The industry in which each firm participates. 3) Size. Sales or income. 4) Cooperation networks. Cooperative ties with diverse agents or organizations, such as: firms, clients, providers, competitors, consultants, universities, and research institutes.

There are three points that highlight the novelty of this work. The first is in regards to the discussion in the existing literature. In general, there is no doubt that cooperation improves the amount of innovative activity in firms, but the empirical evidence of this is centered on data from developed countries - as a result, the argument will not be valid for developing countries. Second, our data incorporates a broader measurement of innovation, as we incorporate technological and non-technological data for various industrial sectors. Third, the econometric technique we used recognizes the problem of zero abundance and allows us to estimate a first innovative activity, which is a change from 0 to 1 , as well as an increase in innovative activity, which is a change from 1 to greater than 1 . Our hypothesis posits that cooperation plays a relevant role in innovation in the context of a developing country, but with certain differences with respect to developed countries.

\section{Data}

The database used combines two versions of the National Innovation Survey of Chile (ENI- Spanish acronym, 2010 and 2012). This survey is directed by the Chilean Ministry of Economy, Development, and Tourism and collected by the National Statistics Institute (INE- Spanish acronym). The target population of both studies was firms that declared taxes during 2009 and 2011, respectively. The database was comprised of 6,548 firms. The independent variables of the model 
are represented by a human capital vector (number of employees and percentage of professionals and technicians), a variable that defines a characteristic of the market the firm participates in (industrial sector), a variable that represents the size of the firm (measured in level of sales), and variables of networks (cooperation). The question regarding cooperation in the survey seeks an explicit response that implies the declaration of a firm regarding some type of formal link with another institution, whether it be with clients, providers, and/or universities.

The questions that each firm responded to regarding innovation are presented in the following table. All answers to questions about innovation are binary (yes/no).

\begin{tabular}{l|l}
\hline Type of Innovation & Questions \\
\hline Product & $\begin{array}{l}\text { 1. Was the product innovation new for the market? } \\
\text { 2. Was the product innovation new for your firm? }\end{array}$ \\
\hline \multirow{3}{*}{ Process } & $\begin{array}{l}\text { 1. Did your firm introduce a new or significantly improved method for manufacturing or producing goods or services? } \\
\text { 2. Did your firm introduce a new or significantly improved method of logistics, delivery or distribution of supplies, goods, or services? } \\
\text { 3. Did your firm introduce a new or significantly improved support activity for its processes, such as a maintenance system or pur- } \\
\text { chase transactions, accounting, or IT? }\end{array}$ \\
\hline \multirow{3}{*}{ Marketing } & $\begin{array}{l}\text { 1. Did your firm introduce significant changes in the design, packaging, or boxing of products (goods and services)? } \\
\text { 2. Did your firm introduce new means or techniques for promoting the product? }\end{array}$ \\
& $\begin{array}{l}\text { 3. Did your firm introduce new methods for the distribution channels of the product? } \\
\text { 4. Did your firm introduce new methods of pricing of goods or services? }\end{array}$ \\
\hline \multirow{2}{*}{ Organizational methods } & $\begin{array}{l}\text { 1. Did your firm introduce new negotiation practices for the organization of processes? } \\
\text { 2. Did your firm introduce new methods for organizing responsibilities and decision-making? } \\
\text { 3. Did your firm introduce new methods for organizing external relationships with other firms or public institutions? }\end{array}$ \\
\hline
\end{tabular}

Source: Own elaboration using ENI survey data

The survey questions that each firm responded to regarding cooperation are: Do you conduct cooperation activities with other businesses or institutions in any of the innovative activities conducted? Are providers a source of information for you? Are clients a source of information for you? Are universities a source of information for you? ... There are similar questions for other possible cooperative agents.

The first variable is called Cooperation, and the following three are considered variables of cooperation with providers, clients, and universities. All answers are binary (yes/no).
The combination of the two original databases showed 8,267 observations. We decided to restrict the base to ultimately 6,548 observations to improve the sales distribution of firms. We developed a histogram demonstrating how sales distribution changed for firms before and after the restriction. We applied a restriction to the companies' sales rank, sales less than or equal to 11,000 million Chilean pesos. The criterion to apply the restriction was to eliminate data far from a normal distribution (Figure 1).

Figure 1:

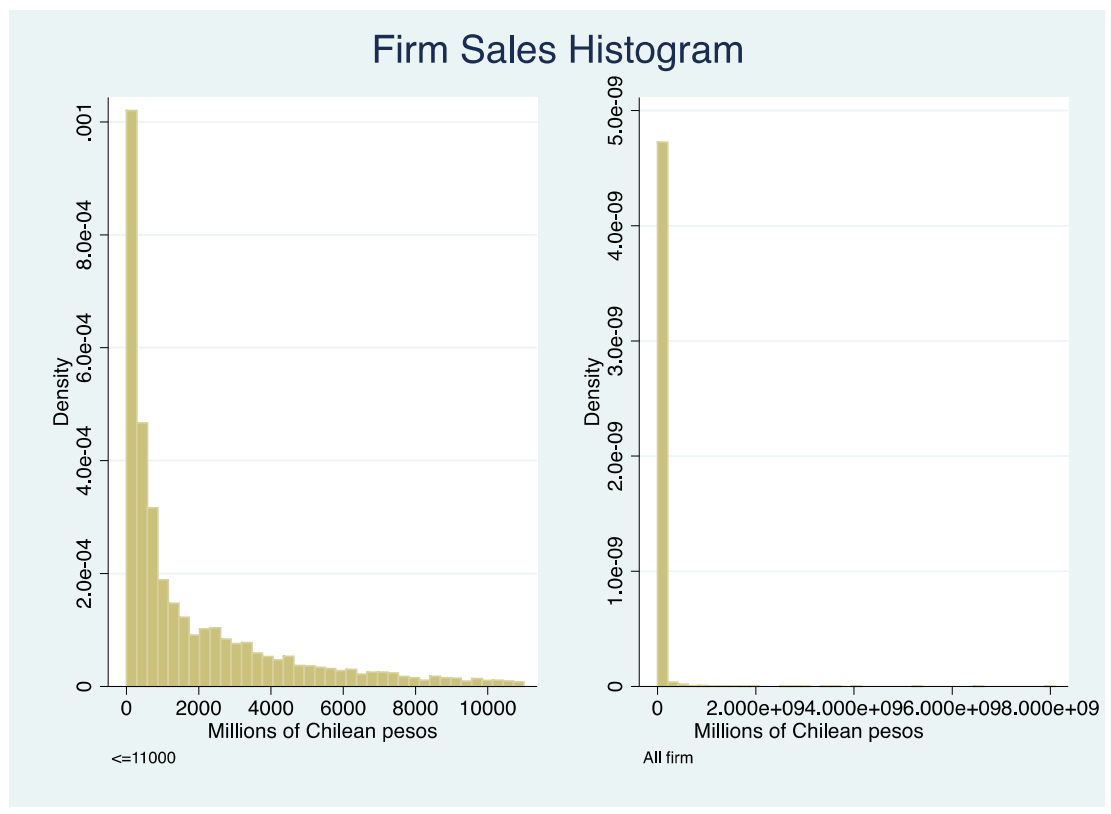

Source: Own elaboration

ISSN: 0718-2724. (http://jotmi.org)

Journal of Technology Management \& Innovation ( ) Universidad Alberto Hurtado, Facultad de Economía y Negocios. 


\section{Econometric strategy}

We used a zero-inflated negative binomial regression (ZINB) to estimate the number of annual innovative activities of firms. The dependent variable is a set of natural numbers where the range of innovative activities moves between 0 (no innovation) and 12 innovative activities.

A ZINB model is a standard econometric approach to contexts where the nature of the dependent variable is the counting of events. That means such a variable is a non-negative integer. The zero-inflated models divide the estimation in two parts; one part estimates the probability to change the event from 0 to 1 , which follows a logit or probit model; and a second part, which considers the count $(1,2,3, \ldots)$ assuming a negative-binomial distribution, for the case of a ZINB. This econometric strategy is the best option when a count model has a high proportion of zeros in the outcome variable, and that is the reason for the logit distribution part into the estimation (Cameron \& Trivedi, 2013).

Regarding the interpretation of the estimated parameters, it is possible to use the signs of both the count and binary models to interpret the direction of the effect of the independent variable, but the precise estimate requires the estimation of the marginal effects. Given the non-linear specification of our model, the marginal effect of each variable does not correspond to each estimated parameter, so we needed to estimate the marginal effect complementarily. As it is a combined model, the binary part allowed us to estimate the changes of $\{0,1\}$ innovative activities and the count part allowed us to estimate the innovative activities $\{2,12\}$.

The methodology of this article addressed three situations through the proposed model. First, the dependent variable had an excessive number of zeros which skewed its empirical distribution (Greene, 2008; Lambert, 1992). Second, we are interested in the dichotomic decision to innovate or not, as well as the number of innovative activities. Third, the focus of the study is in the effect of cooperation. This variable, given the characteristics of the base used, is dichotomic. The ZINB model allows us to address these three situations.

The advantage of our focus stems from the fact that we can econometrically model the dependent variable as a discrete magnitude, as well as establishing which determinants affect the magnitude of said innovative activity, without losing sight of the effect of cooperation. One limitation is that each innovation activity is built in an additive manner, and as such, its weight is ordinal, meaning that the model assumes that each contributes equally with the same weight. Future studies should attempt to improve the limitations of this focus.

\section{Descriptive analysis}

In this section, we will present relevant, descriptive statistical evidence, separating the innovative firms from the non-innovative ones. This is a first approximation of the differences between the groups.

Table 2. Innovative and Non-innovative Firms

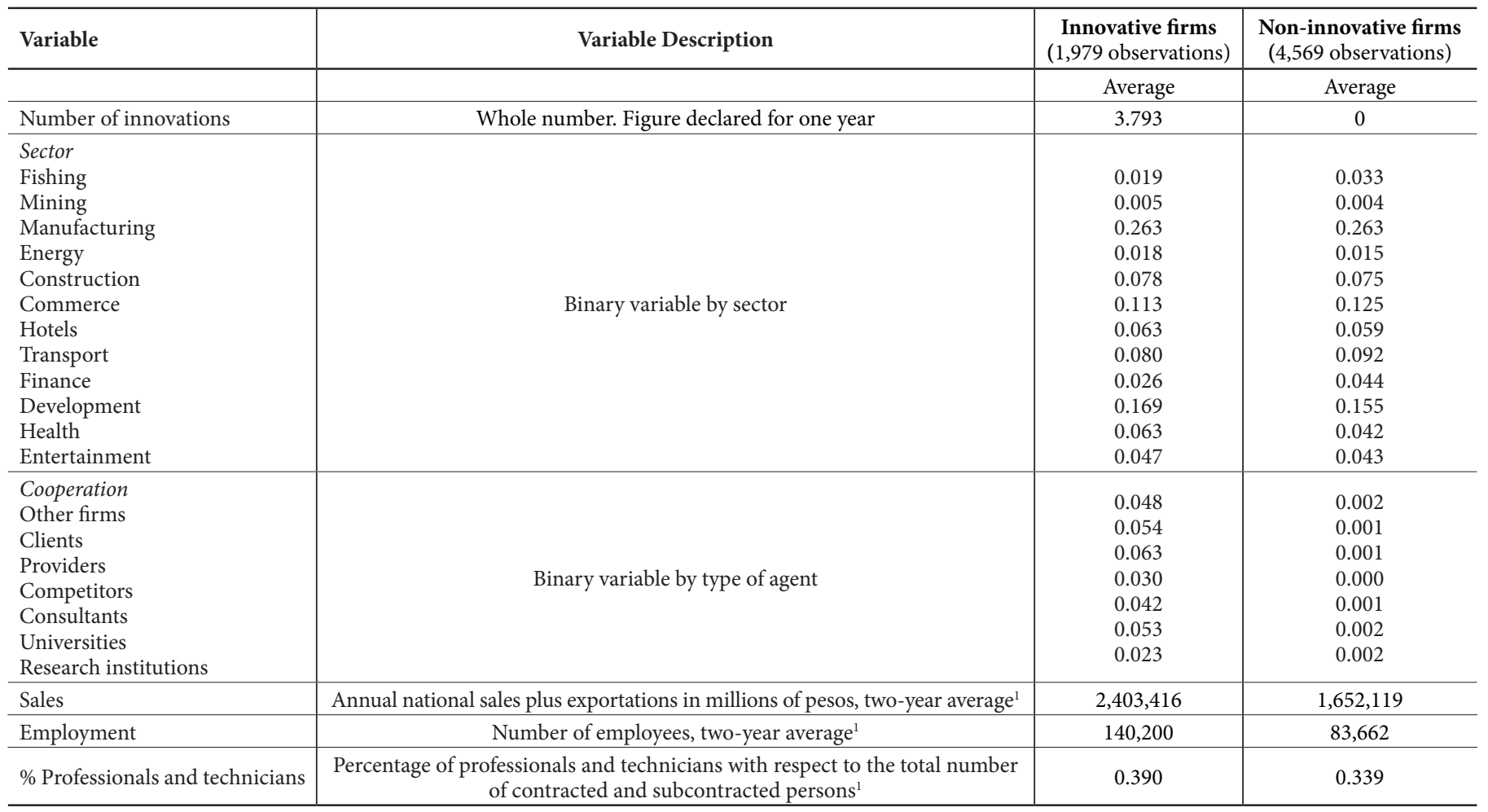

Note: ${ }^{1}$ The statistic corresponds to an average from two years. This average was constructed based on figures declared by the firms. It is necessary to remember that the base used corresponds to the fusion of two cross-sectional surveys, where it cannot be known if a firm had participated in both surveys. For the 2010 survey (7ma), the firms declared sales numbers for 2009 and 2010. For the 2012 survey (8va), the firms declared sales numbers for 2011 and 2012.

Source: Own elaboration based on the 2010 and 2012 National Survey of Innovation. 
In order to demonstrate innovation from a general perspective, Table 2 separates innovative firms and non-innovative firms and incorporates both technological and non-technological types. We found that $30 \%(1,979 / 6,548)$ of firms are innovative and that there are important differences in the averages of almost all variables between both groups. Innovative firms have on average 140,200 employees, of which around $39 \%$ are qualified technicians. Annually, these firms have average sales that border 3.5 billion $^{1}$ USD. Finally, and of considerable interest to us, $5 \%$ of firms that innovate declared that they cooperate with other businesses-clients-universities. $6 \%$ of the firms do some type of cooperation with providers, $4 \%$ with consultants, $3 \%$ with competitors, and 2\% with Research Institutions.

It is interesting to notice there is a Pearce-correlation between 38$72 \%$ among the innovation types and cooperation types (tables A.1 and A.2 at the appendix). This provides some intuition on how these elements are related.

\section{Results}

There are three things that must be mentioned before interpreting Table 3. First, as we elaborated in the economic modeling section, the count model allowed us to infer the number of innovative activities, and the inflated model (Probit) made it possible for us to calculate the probability of starting the first innovative activity. Second, we have three groups of variables to analyze: the effects of the industrial sectors, the types of cooperation, and the individual characteristics of the businesses. Third, this is a first interpretation of the data, given that upon reviewing the marginal effects we can better appreciate the magnitudes. The results of the estimations will be interpreted following the three previous points.

Regarding the industrial sectors, seven sectors presented significant effects in the estimation: Manufacturing, Construction, Commerce, Hotels, Transport, Health, and Entertainment. The number of annual innovative activities in these sectors is significantly greater than in others.

Regarding cooperation, three types of agents showed significance: cooperation between firms, clients, and consultants. The cooperation between firms and these types of agents entails a significant rise in annual innovation activities.

The dispersion coefficient alpha was used to check if ZINB is the better approach for this analysis, instead of using a Poisson distribution for counting (ZIP). The alpha's confidence interval was [0.52; 0.77], which means it was statistically different from zero (hence, $\log (a l p h a)$ is not negative infinity), which means a ZINB model had a better fit than a ZIP.

A probit model was also implemented as a robustness check, where the outcome variable was 1 when the firm performed at least one innovation activity, and zero otherwise. The estimation delivers parameters with very close estimators, in terms of size and signs. Nevertheless, these coefficients are not discussed in this paper. This is due to the fact that the binary nature of the outcome variable hides the effect of the counting, which is the very sense of the phenomenon under scrutiny here.

Table 3: Estimations

\begin{tabular}{|c|c|c|c|c|c|c|}
\hline \multirow[b]{3}{*}{ Variables } & \\
\hline & \multicolumn{4}{|c|}{ ZINB model } & \multicolumn{2}{|c|}{ Probit model } \\
\hline & Count & $\mathrm{SD}$ & Inflated & SD & & \\
\hline Fishing & -0.130 & $(0.185)$ & & & $-0.302^{\star \star}$ & $(0.145)$ \\
\hline Mining & -0.054 & $(0.326)$ & & & 0.239 & $(0.270)$ \\
\hline Manufacturing & $0.196^{*}$ & $(0.104)$ & & & $0.143^{\star}$ & $(0.085)$ \\
\hline Energy & 0.022 & $(0.188)$ & & & -0.063 & $(0.164)$ \\
\hline Construction & $0.215^{\star}$ & $(0.124)$ & & & 0.138 & $(0.101)$ \\
\hline Commerce & $0.212^{*}$ & $(0.116)$ & & & 0.047 & $(0.094)$ \\
\hline Hotels & $0.543^{* * *}$ & $(0.128)$ & & & $0.353^{* * *}$ & $(0.107)$ \\
\hline Transport & $0.339^{* * *}$ & $(0.122)$ & & & 0.123 & $(0.099)$ \\
\hline Finance & -0.110 & $(0.168)$ & & & $-0.257^{\star}$ & $(0.132)$ \\
\hline Development & 0.150 & $(0.109)$ & & & 0.104 & $(0.093)$ \\
\hline Health & $0.394^{* * *}$ & $(0.129)$ & & & $0.276^{\star *}$ & $(0.115)$ \\
\hline Entertainment & $0.389^{* * *}$ & $(0.137)$ & & & $0.265^{\star *}$ & $(0.113)$ \\
\hline Firm cooperation & $0.201^{\star}$ & $(0.121)$ & & & $0.423^{\star *}$ & $(0.192)$ \\
\hline Client cooperation & $0.447^{* * *}$ & $(0.123)$ & & & $0.813^{* * *}$ & $(0.191)$ \\
\hline Provider cooperation & 0.169 & $(0.110)$ & & & $0.916^{* * *}$ & $(0.167)$ \\
\hline Competitor cooperation & -0.097 & $(0.142)$ & & & $0.808^{* * *}$ & $(0.256)$ \\
\hline Consultant cooperation & $0.287^{\star *}$ & $(0.129)$ & & & $0.447^{\star \star}$ & $(0.205)$ \\
\hline University cooperation & 0.116 & $(0.114)$ & & & $0.580^{* * *}$ & $(0.173)$ \\
\hline Institution cooperation & 0.177 & $(0.153)$ & & & 0.259 & $(0.224)$ \\
\hline Survey Version & $0.190^{* * *}$ & $(0.045)$ & & & $0.125^{\star * *}$ & $(0.037)$ \\
\hline Sales & & & $-1.4 \mathrm{e}-4^{* * *}$ & $(1.5 e-5)$ & $6.3 e-5^{* * *}$ & $(7.6 e-6)$ \\
\hline Employment & & & $-4.8 \mathrm{e}-4^{\star *}$ & $(1.8 \mathrm{e}-4)$ & $7.4 \mathrm{e}-5^{\star}$ & $(4.2 \mathrm{e}-5)$ \\
\hline Technicians and professionals & & & $-0.519^{* * *}$ & $(0.094)$ & $0.229^{* * *}$ & $(0.060)$ \\
\hline Constant & $0.698^{* * *}$ & $(0.104)$ & $0.988^{* * *}$ & $(0.059)$ & $-1.224^{\star * *}$ & $(0.083)$ \\
\hline Observations & 6,548 & & 6,548 & & 6,548 & \\
\hline $\log ($ alpha $)$ & $-0.450^{* * *}$ & $(0.097)$ & & & & \\
\hline
\end{tabular}

${ }^{*}$ significance at $10 \%,{ }^{* *}$ significance at $5 \%,{ }^{* * *}$ significance at $1 \%$

${ }^{1} \$ 1$ USD $=\$ 678.06$ Chilean pesos. Therefore $\$ 4,403,416$ million Chilean pesos is equivalent to $\$ 3,544,560,000$ USD. 
With respect to the variables we are calling individual, sales, the number of workers, and the percentage of professionals and technicians, we found that they push the firms to their first innovative activity. The negative signs only reflect the change from 0 to 1 , and upon reviewing the marginal effects, we can more clearly see the magnitude and sign of this estimated parameter.

After controlling for industrial sectors and a group of individual variables, the main results of this section indicated that certain types of cooperation have an effect on a firm's annual innovation activities, and other types of cooperant agents do not. In particular, cooperation with firms, clients, and consultants has a significant effect in this context. Cooperation with providers, competitors, universities, and institutes does not have a significant effect. The significant and positive effect of cooperation with clients, consultants, and firms on the annual innovative activities of the firms stands out in Table 3. Within the context of developing countries, these three types of cooperation seem to be more efficient when innovating.

For an even more thorough analysis, Table 4 shows the estimations of the marginal effects of the ZINB model.

Table 4: Marginal effects of the ZINB estimate

\begin{tabular}{lcc}
\hline Variables & Marginal Effect & $\begin{array}{c}\text { Standard } \\
\text { deviation }\end{array}$ \\
\hline Fishing & -0.143 & $(0.204)$ \\
Mining & -0.0589 & $(0.359)$ \\
Manufacturing & $0.216^{*}$ & $(0.115)$ \\
Energy & 0.0237 & $(0.207)$ \\
Construction & $0.236^{*}$ & $(0.136)$ \\
Commerce & $0.233^{*}$ & $(0.128)$ \\
Hotels & $0.598^{* * *}$ & $(0.142)$ \\
Transport & $0.373^{* * *}$ & $(0.136)$ \\
Finance & -0.121 & $(0.185)$ \\
Development & 0.165 & $(0.120)$ \\
Health & $0.433^{* * *}$ & $(0.142)$ \\
Entertainment & $0.429^{* * *}$ & $(0.152)$ \\
Firm cooperation & $0.222^{*}$ & $(0.133)$ \\
Client cooperation & $0.492^{* * *}$ & $(0.136)$ \\
Provider cooperation & 0.186 & $(0.121)$ \\
Competitor cooperation & -0.107 & $(0.156)$ \\
Consultant cooperation & $0.316^{* *}$ & $(0.143)$ \\
University cooperation & 0.127 & $(0.126)$ \\
Institute cooperation & 0.194 & $(0.169)$ \\
Survey version $(2010 / 2012)$ & $0.209^{* * *}$ & $(0.0507)$ \\
Sales & $9.08 \mathrm{e}-05^{* * *}$ & $(9.53 \mathrm{e}-06)$ \\
Employment & $0.000314^{* * *}$ & $(0.000121)$ \\
Proportion of professionals to & $0.337^{* * *}$ & $(0.0603)$ \\
technicians & 6,548 & \\
Observations & & \\
\hline Note: & & \\
$\star * *$ p $<0.01,{ }^{* *}$ p $<0.05, * \mathrm{p}<0.1$ & & \\
& & \\
\hline
\end{tabular}

Table 4 shows the positive and significant effect of Manufacturing, Construction, Commerce, Hotels, Transport, Health, and Entertainment. This indicates that firms that participate in these industrial sectors would have greater probabilities of innovating, according to our estimates. In particular, Hotels, Health, and Entertainment are the sectors that present the greatest magnitudes. The more cooperation with firms, clients, and consultants is presented with significant and positive values, the greater the magnitude of cooperation with clients and consultants. This implies that firms that cooperate with clients, consultants, and other firms present greater probabilities of innovating. Regarding the group of individual sales variables, employment, and the percentage of professionals and technicians, we noted a highly significant positive sign. This implies that the size of the firm, measured in sales, number of employees, and the proportion of professionals and technicians, are variables that positively affect the probability of innovation for a firm. The version of the survey is also significant and positive, which helps us control for any temporal effect that may have changed the year the survey was conducted. It should be noted again that we utilized a database that incorporates two other groups of surveys that were taken in different years.

Figure 2 presents an econometric post-estimation analysis. The objective was to analyze the expected marginal effects of the previously calibrated model. Graphics 2 and 3 were created to project the expected innovative activities starting with the evolution of sales and the number of employees when firms cooperate with clients and when they do not.

Figure 2.

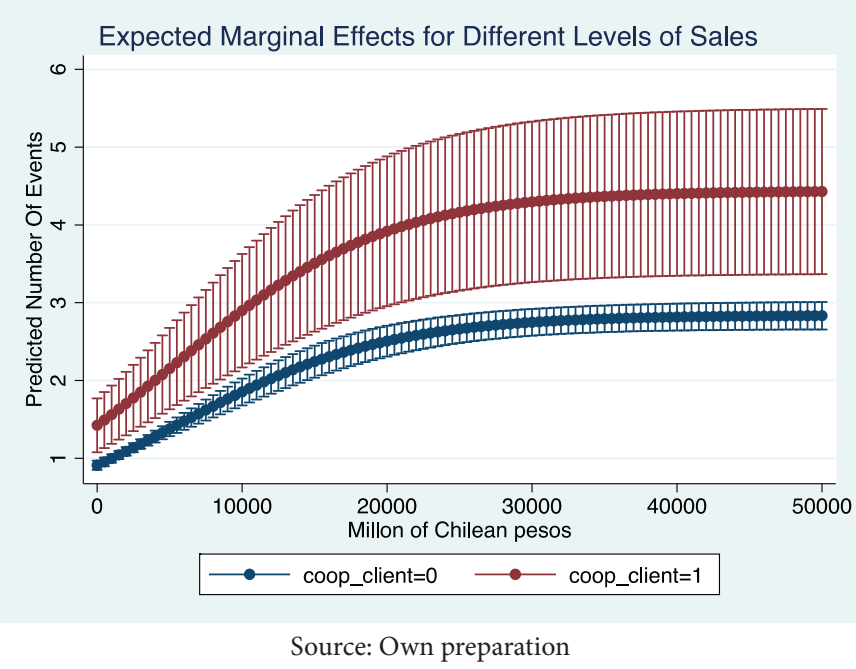

Figure 3.

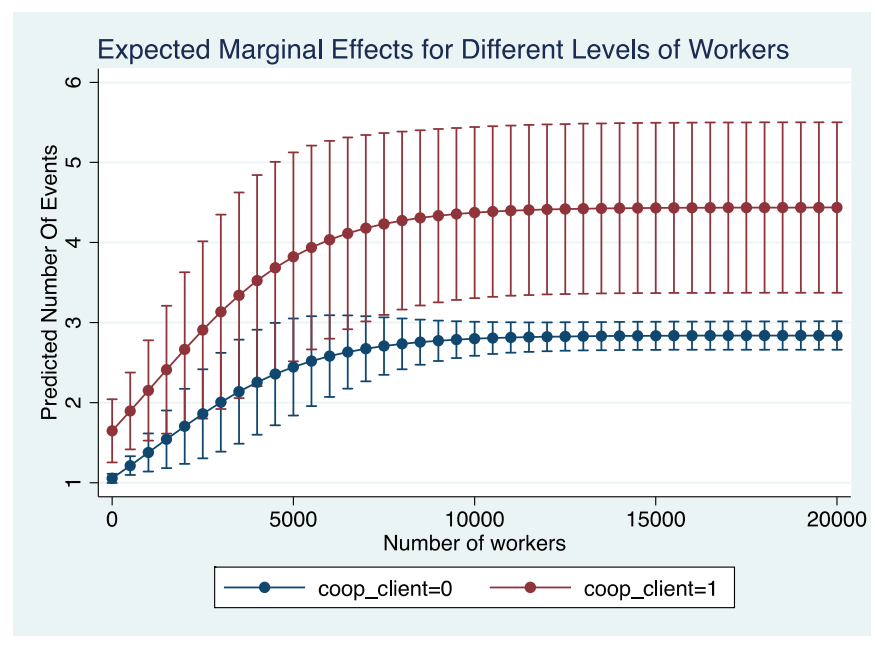

Source: Own elaboration 
Figure 2 demonstrates that when there is no cooperation with clients, the expected innovative activity starts under 1 and advances quite marginally as the size of the firm (measured in sales) grows, arriving at a value under 3 innovative activities per year. When there is cooperation with clients, the initial expected effect starts over 1 activity per year and moves up to more than 4 and less than 5 annual activities as the size of the firm grows. A similar analysis is presented as the number of employees grows (see Graphic 3). The results are similar to those of Graphic 2.

These results show the significance of cooperation, but even more interestingly, they show that its mere existence is not a guarantee of a causal effect. In aggregate terms, a firm that does one innovative activity per year on average without cooperating could experience an increase to 4 annual innovative activities if they incorporated more cooperation activities with clients - thereby quadrupling their possibilities for innovation.

\section{Discussion}

The most cited studies on the topic of business innovation measure innovation from a technological perspective focused on invention patents. A primary example of this is the work of Jaffe, Trajtenberg, \& Henderson (1993), and their study on the geographical locations of new patents compared to the location of patents cited within the United States. The study showed that it is likely that new patents will originate from the United States and from the same state, which highlights the importance of location. The work of Lissoni, Llerena, McKelvey, \& Sanditov (2008) also centers its focus on patent creation as a way to measure innovation, providing statistics outlined in a database of academic patents in France, Italy, and Sweden. They showed that the contribution of European universities to national patents does not seem to be significantly less intense than that of its American homologues. The work of Jensen, Wenster, \& Buddelmeyer (2008), while also using patents to measure innovation, centered its primary interest on the determining factors of a firm's survival. They demonstrated that, among other factors, innovation influences firm survival. Other studies such as Mansfield (1986), Acs \& Audretsch (1988) and Heller (1998) also consider patents as a measurement of innovation. We recognize that these previous studies are an important contribution to knowledge about innovation, but we also believe that looking at innovation solely from the perspective of patents is provides an incomplete perspective on this subject. Our focus when measuring innovation was not on patents, but on a broader and more novel measurement of innovation that incorporates both a technological and non-technological approximation. This measurement of innovation is also recognized by the OECD's literature on innovation (OECD, 2005). Furthermore, we believe that this is a better measurement for understanding innovative activities in the contexts of developing countries.

There are experiences in developed countries using broader measures of innovation, such as the case of De Faria \& Schmidt (2012). They studied the cases of Portugal and Germany, analyzing the factors that push private firms to cooperate with partners from other countries in innovation activities, an incorporated non-technological innovation in their innovation measurements. Their work uses the Community Innovation Survey III (CIS), a survey based on the manual of Oslo (OECD, 2005), as a base. This comparison is interesting, as they contrasted a country oriented toward the exportation of high technology, Germany, with a country that is highly dependent on imports and is characterized by a strong tertiary industry, Portugal. Even with these structural differences, the authors demonstarted that both foreign and national cooperation have significant effects on the levels of innovation, delivering new information regarding the relationship between both variables for different economic contexts. The studies of Torres \& De la Fuente (2011), van Uden, Knoben, \& Vermeulen (2016), and Waheed (2017) used CIS and as such, utilized the directories of the OECD as a base. In particular, Torres \& la Fuente (2011) measured the innovations of a group of tourism firms in the city of Pucón, Chile, which provided evidence in the context of a developing country. Using data from 13 countries in Europe, Srholec (2014) analyzed the measure in which national macroeconomic conditions show the propensity of firms to cooperate in innovation nationally and internationally. The results indicated strong differences between the countries on this last point. The firms that operated in countries with less developed research infrastructures have a higher propensity for cooperating with foreign partners. Thus, size and openness of the economy are relevant factors. Geldes, Heredia, Felzensztein, \& Mora (2017) conducted a study within the context of a developing country using a broader measure of innovation: they focused on geographical proximity (spatial) to study the determinants of cooperation in the Chilean agro-industry. They modeled the behavior of 312 firms, and demonstrated that spatial proximity to other organizations is a factor that supports cooperation, and in turn that cooperation influences innovation. From this group of authors and studies, we want to highlight two ideas: first, using measurements of innovation broader than patents is a reality and an important contribution, in the sense that it adds factors through which to measure this phenomenon. Second, the focus of the empirical evidence is mainly centered on the experiences of developed countries, while the evidence for developed countries is scarce, which opens and drives this discussion.

Pippel (2014) also contributes to the discussion by adding a perspective of non-technological innovation. This study distinguished seven different types of cooperation utilizing data from Germany, a developed country. This study proved to be an interesting basis from which to discuss the results of the present manuscript. The estimates showed that cooperation with other firms, providers, consultants, and universities are significant variables when performing non-technological innovation activities. The effect of said variables was positive, and its base had 2,417 observations. In our case, we used the situation of Chile in Latin America, a developing country. Using a base of 6,548 observations, considering both technological and non-technological innovations, we found that the significant types of cooperants were other firms, clients, and consultants. The comparison has its limitations given that the dependent variable is slightly different: Pippel (2014) studied non-technological innovation and we studied both technological and non-technological innovation. However, the group of independent variables in both cases is similar. Upon comparing 
the two, we noted interesting differences, given that cooperating with other firms and consultants is relevant in both contexts. Cooperation with universities and providers did not turn out to be significant for the context developing country, which could be a product of this same context, given that a developing country could be farther from high value productions and closer to raw material production. Cooperating with clients was not found to be significant in the context of a developed country, but it was found to be significant in a developing country. A possible explanation for this finding that, given the maturity of firms in developing countries, they might seek to close deals more quickly with their clients.

An idea that we do not incorporate in this document, but which could be an interesting idea for future work, is reverse causality. The work of Baraldi, Cantebene \& Perani (2013) give an approach this idea. If we apply the concept of reverse causality, in our document, it would be equivalent to thinking that not only cooperation that influences innovative activities, but that, innovative companies could be more willing to cooperate.

The results of our study provide a contribution to the discussion on innovation and cooperation, given that we found differences in the ways that firms address cooperation within different contexts. The type of agent that the firm cooperates with changes depending on the level of development of the country in which it is located.

\section{Conclusions}

There is abundant empirical evidence that supports the relationship between cooperation and innovative business activity in developed countries, but the discussion continues to be scarce in the context of developing countries.

In the context of a developing country, a firm that reports on cooperation conducts more innovative activities per year than those that do not. The type of agent with which they cooperate is relevant in this context. In particular, other firms, clients, and consultants showed stronger and more stable results than cooperation with other types of agents.

The novelty of the study lies in our demonstration of the fact that there are differences in the effect of cooperation on innovative activities in firms from developed and developing countries. Also, our data incorporates a broader measure of innovation, as we incorporate technological and non-technological innovations for various industrial sectors. Lastly, the econometric technique used recognizes the problem of the abundance of zeros and allowed us to estimate both a first innovative activity, which is to say a change from 0 to 1 , and an increase in innovative activity, i.e. a change from 2 to 12.

Our results provide a significant contribution to the discussion on innovation and cooperation, given that we found differences in how firms address cooperation when the context is different. The type of agent the firm decides to cooperate with changes when we change the context from a developed country to a developing one. These results could help to focus the efforts of private or public institutions that support innovation processes in firms, especially in developing countries.
Future studies should analyze various reasons that may explain why the type of agent the firm decides to cooperate with is different between the contexts of developed and developing countries. Furthermore, this study should be replicated with the same technique for measuring innovation, since the results of Pippel (2014), with which the results of the present work are compared, considered non-technological innovations, and our study considered both technological and non-technological innovations. Future studies should also utilize larger bases on a national level, as in the case of Goel \& Nelson (2018). Lastly, more multi-disciplinary studies should be developed, since studies such as those of Jones, Klapper, Ratten, \& Fayolle (2018) highlight that in order to deepen our knowledge, a focus that involves various disciplines is necessary.

\section{Acknowledgements}

We would like to give a special thank you to Dr. David Fleming, Senior Research Economist at the Commonwealth Scientific and Industrial Research Organisation (CSIRO) for his valuable comments and suggestions for the development of this manuscript.

\section{Bibliography}

Acs, Z., \& Audretsch, D. (1988). Innovation in Large and Small Firms: An Empirical Analysis. American Economic Review, 78(4), 678-690.

Baraldi, A., Cantabene, C \& Perani, G. (2014). Reverse causality in the R\&D-patents relationship: an interpretation of the innovation persistence. Economics of Innovation and New Technology, 23(3), 304-326. https://doi.org/10.1080/10438599.2013.848059

Cameron, A. C., \& Trivedi, P. K. (2013). Regression analysis of count data (Vol. 53). Cambridge university press.

De Faria, P., \& Schmidt, T. (2012). International cooperation on innovation: Firm-level evidence from two European countries. Innovation, 14(3), 303-323. http://doi.org/10.5172/impp.2012.14.3.303

de Mel, S., McKenzie, D., \& Woodruff, C. (2009). Innovative Firms or Innovative Owners? Policy Research Working Paper. Retrieved from http://documents.worldbank.org/curated/en/276891468166787383/ pdf/WPS4934.pdf

Dyer, J. H. (1996). Specialized Supplier Networks as a Source of Competitive Advantage: Evidence From The Auto Industry. Strategic Management Journal, 17(4), 271-291. http://doi.org/10.1002/(SICI)10970266(199604)17:4<271::AID-SMJ807>3.0.CO;2-Y

Dyer, J. H., \& Nobeoka, K. (2000). Creating and managing a highperformance knowledge-sharing network: the Toyota case. Strategic Management Journal, 21(3), 345-367. http://doi.org/10.1002/ (SICI) 1097-0266(200003)21:3<345::AID-SMJ96>3.3.CO;2-E

Fagerberg, J., Mowery, D. C., \& Nelson, R. R. (Eds.). (2006a). The Oxford Handbook of Innovation, 8, 95-107. http://doi.org/10.1093/ oxfordhb/9780199286805.001.0001 
Fagerberg, J., Mowery, D., \& Nelson, R. (2006b). The Oxford Handbook of Innovation. (J. Fagerberg, D. C. Mowery, \& R. R. Nelson, Eds.) (1st ed.). Oxford University Press. http://doi.org/10.1093/oxfordhb/9780199286805.001.0001

Friedman, Y., \& Carmeli, A. (2017). The influence of decision comprehensiveness on innovative behaviors in small entrepreneurial firms: the power of connectivity. Innovation, 20(1), 61-83. http://doi. org/10.1080/14479338.2017.1369141

Fuentes Solís, R., \& Ferrada Rubio, S. (2016). Innovación Tecnológica en Empresas Chilenas: Un Estudio Empírico Basado en Patentes. Journal of Technology Management \& Innovation, 11(4), 56-64. http:// doi.org/10.4067/S0718-27242016000400008

Geldes, C., Heredia, J., Felzensztein, C., \& Mora, M. (2017). Proximity as determinant of business cooperation for technological and non-technological innovations: a study of an agribusiness cluster. Journal of Business \& Industrial Marketing, 32(1), 167-178. http://doi. org/10.1108/JBIM-01-2016-0003

Goel, R. K., \& Nelson, M. A. (2018). Determinants of process innovation introductions: Evidence from 115 developing countries. Managerial and Decision Economics, 39(5), 515-525. http://doi.org/10.1002/mde.2922

Greene, W. (2008). Functional forms for the negative binomial model for count data. Economics Letters, 99(3), 585-590. http://doi. org/10.1016/j.econlet.2007.10.015

Heller, M. A. (1998). Can Patents Deter Innovation? The Anticommons in Biomedical Research. Science, 280(5364), 698-701. http:// doi.org/10.1126/science.280.5364.698

Heredia Pérez, J. A., Geldes, C., Kunc, M. H., \& Flores, A. (2019). New approach to the innovation process in emerging economies: The manufacturing sector case in Chile and Peru. Technovation, 79, 35-55. http://doi.org/10.1016/j.technovation.2018.02.012

Hippel, von, E. (1987). Cooperation between rivals: Informal know-how trading. Research Policy, 16(6), 291-302. http://doi. org/10.1016/0048-7333(87)90015-1

Jaffe, A. B., Trajtenberg, M., \& Henderson, R. (1993). Geographic Localization of Knowledge Spillovers as Evidenced by Patent Citations. The Quarterly Journal of Economics, 108(3), 577-598. http://doi.org/10.2307/2118401

Jensen, P. H., Wenster, E., \& Buddelmeyer, H. (2008). Innovation, Technological Conditions and New Firm Survival ${ }^{\star}$. Economic Record, 84(267), 434-448. http://doi.org/10.1111/j.1475-4932.2008.00509.x

Jones, P., Klapper, R., Ratten, V., \& Fayolle, A. (2018). Emerging themes in entrepreneurial behaviours, identities and contexts. The International Journal of Entrepreneurship and Innovation, 19(4), 233236. http://doi.org/10.1177/1465750318772811

Lambert, D. (1992). Zero-Inflated Poisson Regression, With an Application to Defects in Manufacturing. Technometrics, 34(1), 1-14.
Lissoni, F., Llerena, P., McKelvey, M., \& Sanditov, B. (2008). Academic patenting in Europe: new evidence from the KEINS database. Research Evaluation, 17(2), 87-102. http://doi.org/10.3152/095820208X287171

Mansfield, E. (1986). Patents and Innovation: An Empirical Study. Management Science, 32(2), 173-181. http://doi.org/10.1287/mnsc.32.2.173

Marsh, D. (2004). An Investigation into the Determinants of Innovation in the New Zealand Biotechnology Sector. The University of Waikato, Hamilton, New Zealand.

OECD. (2005). Oslo Manual (3rd ed.) (pp. 1-166).

Pippel, G. (2014). R\&D cooperation for non-technological innovations, 1-21. http://doi.org/10.1080/10438599.2013.871167

Powell, W. W. (1996). Inter-organizational collaboration in the biotechnology industry. Journal of Institutional and Theoretical Economics, 152(1), 197-215. http://doi.org/10.2307/40751919

Rosenkpf, L., \& Tushman, M. L. (1998). The Coevolution of Community Networks and Technology: Lessons from the Flight Simulation Industry. Industrial and Corporate Change, 7(2), 311-346. http://doi. org/10.1093/icc/7.2.311

Srholec, M. (2014). Understanding the diversity of cooperation on innovation across countries: multilevel evidence from Europe. Economics of Innovation and New Technology, 24(1-2), 159-182. http:// doi.org/10.1080/10438599.2014.897864

Torres, C., \& De la Fuente, H. (2011). Determinantes de la innovación en empresas de turismo en Pucón-Chile. Panorama Socioeconómico, 29(42), 24-42.

van Uden, A., Knoben, J., \& Vermeulen, P. (2016). Human capital and innovation in Sub-Saharan countries: a firm-level study. Innovation, 19(2), 103-124. http://doi.org/10.1080/14479338.2016.1237303

Wadho, W., \& Chaudhry, A. (2018). Innovation and firm performance in developing countries: The case of Pakistani textile and apparel manufacturers. Research Policy, 47(7), 1283-1294. http://doi. org/10.1016/j.respol.2018.04.007

Waheed, A. (2017). Innovation and Firm-Level Productivity: Evidence from Bangladesh. The Developing Economies, 55(4), 290-314. http://doi.org/10.1111/deve.12152

Zhu, H., Zhang, M. Y., \& Lin, W. (2016). The fit between business model innovation and demand-side dynamics: catch-up of China's latecomer mobile handset manufacturers. Innovation, 19(2), 146166. http://doi.org/10.1080/14479338.2016.1275979

Zhu, K., Kraemer, K. L., \& Xu, S. (2006). The Process of Innovation Assimilation by Firms in Different Countries: A Technology Diffusion Perspective on E-Business. Management Science, 52(10), 15571576. http://doi.org/10.1287/mnsc.1050.0487 


\section{Appendix}

Table A.1. Pearson correlation of innovation's type and cooperation source

\begin{tabular}{lcc}
\cline { 2 - 3 } & \multicolumn{2}{c}{ Innovation type } \\
\cline { 2 - 3 } & Technological & Non-Technological \\
\hline Client & 0.4106 & 0.7212 \\
Provider & 0.4901 & 0.6217 \\
University & 0.3838 & 0.7127 \\
\hline
\end{tabular}

Table A.1. Pearson correlation of innovation's category and cooperation source

\begin{tabular}{lcccc} 
& \multicolumn{2}{c}{ Table A.1. Pearson correlation of innovation's category and cooperation source } \\
\cline { 2 - 4 } & Production & Innovation in & Orocess & Marketing \\
\cline { 2 - 5 } & 0.4991 & 0.5539 & 0.5593 & 0.4527 \\
Client & 0.4982 & 0.5572 & 0.5517 & 0.4422 \\
Provider & 0.4192 & 0.4663 & 0.4789 & 0.3817 \\
\hline
\end{tabular}

